\title{
DISCURSO DE POSSE DO DESEMBARGADOR FRANCIS DAVIS COMO PRESIDENTE DO TRIBUNAL DE JUSTIÇA DO ESTADO DE SÃO PAULO
}

Excelentíssimo Senhor Doutor Antonio Junqueira, DD. Diretor da Faculdade de Direito da Universidade de São Paulo, Meus Senhores e minhas Senhoras,

Aqui estamos, em nome da mocidade acadêmica da década de 1940 , para deixar em legado aos estudantes de Direito de agora e de sempre, a parte primordial da herança cultural que, por nossa vez, notadamente no dia 9 de novembro de 1943, recebemos da Faculdade do Largo de São Francisco.

Sabemos todos, que o processo educacional, de modo sistematizado ou difuso, engloba, de forma cogente, as mais acalentadas aspirações e tradições de um povo. São precisamente as maneiras de pensar, agir, falar e sentir que identificam e diferenciam esse povo dos demais, de sorte a marcar a sua independência social. É através do processo educacional que as gerações adultas procuram modelar as mais jovens, à imagem de seus mais ardentes ideais.

Nesta amada, e nunca assaz louvada Academia, através de todos os tempos, duas são as linhas mestras, que norteiam o ensino aqui ministrado: no que concerne ao Direito Privado, as regras comportamentais, vindas de Justiniano: "honeste vivere, nemo laedere, suum cuique tribuere." E, no campo do Direito Público, a incessante busca de um Estado verdadeiramente livre e democrático, em que sejam obedecidos, efetivamente, os conceitos vindos da antiga Grécia, de isonomia (de igualdade de todos perante a lei) e de eunomia (de respeito às leis, livremente promulgadas pelo povo, em favor do bem comum).

Daí a situação, verdadeiramente paradoxal, sob o prisma político, em que, como estudantes de Direito, vivíamos naqueles tormentosos anos de 40: aprendíamos, por nossos Mestres e em nossos livros, que a essência de uma administração pública democrática, conforme insculpido no preâmbulo de uma constituição estadual norte-americana, está em um "governo de leis e não de homens." Ao passo que, fora das Arcadas, na vida cotidiana, enfrentávamos o arbítrio infinito daqueles que se haviam apossado, pela violência, do comando da 
Nação, obrigando-nos a repelir, apenas com a nossa coragem e os nossos ideais, os esbirros da cruel ditadura do Estado Novo.

Sonhadores da instituição de um vero Estado de Direito, não nos conformávamos em viver e sofrer sob os desmandos do totalitarismo. Nosso inconformismo, a custo sopitado, era marcado com vibrantes Manifestos à Nação, ou espoucava em ruidosas manifestações só sufocadas a golpes de cacetete ou de prisões arbitrárias, nos cárceres do DOPS, no Largo General Osório.

O confronto fazia parte do nosso cotidiano. Discursos, panfletos, versos, tudo nos servia para afirmar e reafirmar a antítese existente entre a realidade política do País e os nossos sentimentos. Ao tempo, aprestava-se a Força Expedicionária, que iria lutar, na Europa, pela vitória dos regimes democráticos. Parecia-nos contraditório e paradoxal arriscarem-se, alhures, os nossos jovens quando, no Brasil, sem esperanças de mudanças, subsistia pertinaz ditadura. As trovas do colega Norberto Vilela bem traduziam nosso desencanto:

$$
\begin{aligned}
& \text { "Ó valente legionário } \\
& \text { do Corpo Expedicionário, } \\
& \text { Por que vais lutar a esmo? } \\
& \text { Se a luta cruenta e fria, } \\
& \text { é pela democracia, } \\
& \text { Vamos lutar aqui mesmo!" }
\end{aligned}
$$

Descreve Geraldo Vidigal, em seu formoso livro $O$ Aprendiz de Liberdade, a evolução dos acontecimentos, naqueles tensos meses do final do ano de 1943: o "Baile das Américas", em 30 de outubro, patrocinado pelo Centro XI de Agosto, no antigo Esplanada, onde os estudantes recitaram os versos revoltosos e, em côro, bradaram "Morras ao Getúlio"; a prisão, imediata, do Presidente do Centro, o destemido, heróico e saudoso Hélio Motta; a invasão e depredação do Centro, pela Polícia Militar, cuja condenação judicial, anos mais tarde, no pagamento dos danos causados, não reparou suficientemente o agravo perpretado; a passeata, do dia 5 de novembro, do Vale do Anhangabaú até os pórticos da Faculdade de Direito. Finalmente, no dia 9 de novembro, a "passeata do silêncio" quando marchamos, depois de nos amordaçar, com os nossos próprios lenços, até o Largo de São Francisco. E foi ali que, após infrutíferas discussões com os agentes da Ditadura, eles exigindo nossa imediata dispersão, nós defendendo a 
exteriorização da perda de nossa liberdade de expressão, acabamos vítimas de sucessivas descargas de fuzis, ou mesmo, metralhadoras!

Atônitos, de início, pensamos que seriam tiros de festim. Logo depois, quando conforme a primorosa expressão do Professor Mário Mazagão, vimos o rubi de nosso sangue, colorindo a calçada das Arcadas, percebemos que tentavam, verdadeiramente, ceifar as nossas vidas ...

Morreu baleado, no episódio, um estudante, Jaime Silva Telles, que ainda não ingressara nos quadros da Faculdade, mas que já comungava de nossos ideais. Sairam feridos a tiros, alguns com gravidade, os colegas Aloísio Ferraz Pereira, Haroldo Bueno Magano, Sílvio de Campos Mello, Luiz Affonso Cardoso de Mello Otero e João Brasil Vita.

Protestos, de todo o Brasil, verberaram a repressão totalitária. Uniram-se professores, advogados e outros profissionais liberais. $\mathrm{O}$ ofício, do Instituto dos Advogados, em termos candentes, ao Governador do Estado, dá bem a medida da revolta causada pelo covarde massacre. Mas, infelizmente, não foram bastantes para barrar o rigor na perseguição das nossas pessoas: em janeiro de 1944, foram convocados, a dedo, para integrar a Força Expedicionária Brasileira, quatro reservistas, coincidentemente dos mais destacados estudantes de Direito: Ruy Pereira de Queiroz, José Bernardes, Naldo Caparica e Geraldo Vidigal. Semanas após, outros quatro mais, eram chamados para o serviço ativo do Exército: Luiz Gonzaga Arrobas Martins, José Rubens Prestes Barra, Ricardo Gumbleton Daunt Filho e eu.

Mas, foram outros tantos tiros, que saíram pela culatra: nós que já amávamos a Liberdade e o Direito, não tivemos dificuldade para demonstrar que também amávamos, acendradamente, a nossa Pátria. Se o Exército Brasileiro é uma escola de civismo, provamos que a Faculdade de Direito é um templo de patriotismo. Aqueles que foram para a Itália, voltaram mui justamente aureolados como verdadeiros heróis; e aqueles que serviram no Brasil, em zona de guerra, desempenharam com valor, devoção e eficiência todas as tarefas militares que lhes foram confiadas. De minha parte, tive a honra de receber, doado pela minha Faculdade de Direito, a espada de aspirante premiado, no curso do Oficialato Militar, Turma 1947. 
Por outro lado, os nossos irmãos fardados nos receberam de coração aberto, com integral solidariedade, embora algo constrangidos, na medida em que uma convocação militar pudesse ser havida como mais um instrumento de opressão, e não aquilo que sempre foi, especialmente para nós, isto é, o glorioso privilégio de melhor servir à Pátria, se necessário com o risco da própria vida.

Sofremos outras perseguições que, no final, como a convocação militar, transmudaram-se em galardões do mais alto lavor. Inclusive, por exemplo, alguns de nós foram processados perante o Tribunal de Segurança Nacional, ônus de que só nos livramos quando da volta ao regime democrático, em 1945, beneficiados pela anistia. Não é demais lembrar que, quando do meu concurso de ingresso na Magistratura de nosso Estado de São Paulo, chamado a explicar ao Presidente do Tribunal de Justiça, os antecedentes processuais constantes na minha folha corrida, ouvi do culto, respeitado e sempre saudoso Desembargador Theodomiro Dias, o dignificante e inesquecível comentário: "Essa é uma das raras oportunidades em que antecedentes registrados em folha criminal nobilitam o respectivo portador"

É por todias essas circunstâncias, por todos esses fatos, que nós nos orgulhamos de termos sido Acadêmicos de Direito na década de 1940. Tivemos a honra e a oportunidade de poder provar nosso amor à Pátria e à Liberdade; e de termos tido, em retribuição, a ventura de laurear nossos nomes com o qualificativo da Dignidade, bem como de cercá-los com o respeito e estima de nossos concidadãos. $\mathrm{E}$, pelas mesmíssimas razões, devotamos o maior amor e carinho ao nome, todos os nomes, dos estudantes de Direito que figuram nos quadros de formatura, dos anos de 1940, principalmente daqueles que, em 9 de novembro de 1943, de peito aberto, desarmados, lutaram por seus ideais, na nuas de São Paulo. Todos eles, todos nós, cada qual a seu modo, unidos pelos mesmos ideais, marcamos nossa passagem pelas Arcadas do Largo de São Francisco.

Como dissemos de início, estamos deixando aos estudantes de Direito, de agora e sempre, em legado, todas as glórias, todas as alegrias, todas as insígnias que, por amarmos a Liberdade e a Pátria, adornaram nossos corações. Parodiando Hemingway, podemos proclamar, alto e em bom tom, que os sinos não dobram pelo nosso sangue derramado, nem pelos tiros que nos feriram, nem tampouco pelos dias de injusto cárcere que amargamos, ou pelos sofrimentos que passamos apartados dos nossos familiares e amigos. Ao contrário, isso sim, por nós 
os sinos repicam festivos, alegres e gloriosos, porque, por nossa Faculdade de Direito, pela formação moral e jurídica que nos concedeu, e por nossa querida Pátria, somos, verdadeiramente, abençoados por Deus. Esse mesmo Deus, bom e misericordioso, que inspirou o poeta Oliveira Ribeiro Neto, em seu imortal Canto de Glória da Faculdade de Direito:

"Eu confio e espero, em tua mocidade

Que é a mesma, sempre, velha Faculdade

Pois Ruy, e Rio Branco, e Nabuco e mil outros

Que deram à Pátria seu nome grandioso

Enchendo de luzes páginas da História

Vão mostrando aos moços, por felicidade,

Que o teu nome, sempre, minha Faculdade

É a melhor das rimas para a Liberdade,

É a melhor das chamas para o altar da Glória!"

A seguir, o poeta Paulo Bomfim homenageou os jovens de 1943 com o poema:

\section{AOS MOÇOS DE 43}

Em dias amordaçados

Os jovens foram marchando,

Vinham eles das Arcadas,

Das lutas da Abolição,

Da sagração das trincheiras,

Dos comícios inflamados,

Das barricadas do sonho!

Eram tempos de Novembro,

Eram tempos de inquietude!

Os moços sempre chegando

Dos contrafortes da noite,

Dos planaltos da revolta,

Do mar a pedir justiça! 
Eram tardes de mordaça,

Eram manhãs conspirando!

Meio século depois,

$A$ rebeldia de outrora

Clama por novas auroras,

E a grisalha mocidade

Evoca a maré dos sabres,

E grava a sangue e saudade

Num território infinito,

Sob a bênção das Arcadas,

Esta chama que é chamada,

Santa senha - Liberdade!

\section{Paulo Bomfim}

São Paulo, 9 de novembro de 1943-1993. 